\title{
KALAMKARI:A POWERFUL MEDIUM IN THE FIELD OF FASHION AND ART
}

\author{
Arati Kushwaha
}

\section{INTRODUCTION}

The inspiration for my art derives from ancient Indian tradition. I am fascinated by the artform known as kalamkari. The type of fabric I used in my artwork Monster (2017)' is Machilipatnam (produced at Pedana, a town near Machilipatnam in the Krishna district of the Indian state of Andhra Pradesh), which is associated with block-printed floral designs using vegetable dyes. My artwork embodied the traditional story of a strong woman challenging the world. The fabric itself reflected the story of customary cultural limitations in India. The spirit embodied in these forms challenges these notions in its slowly danced celebration of strength and liberation, of allure and triumph - as in the story of the goddess Durga.

In her 2010 book Goddess Durgā and Sacred Female Power, ${ }^{2}$ Laura Amazzone explores how, in all human societies, an empowered model of the divine and fearless female is absent. Traditional depictions of Durga show a warrior woman with eight hands. Her sacred female

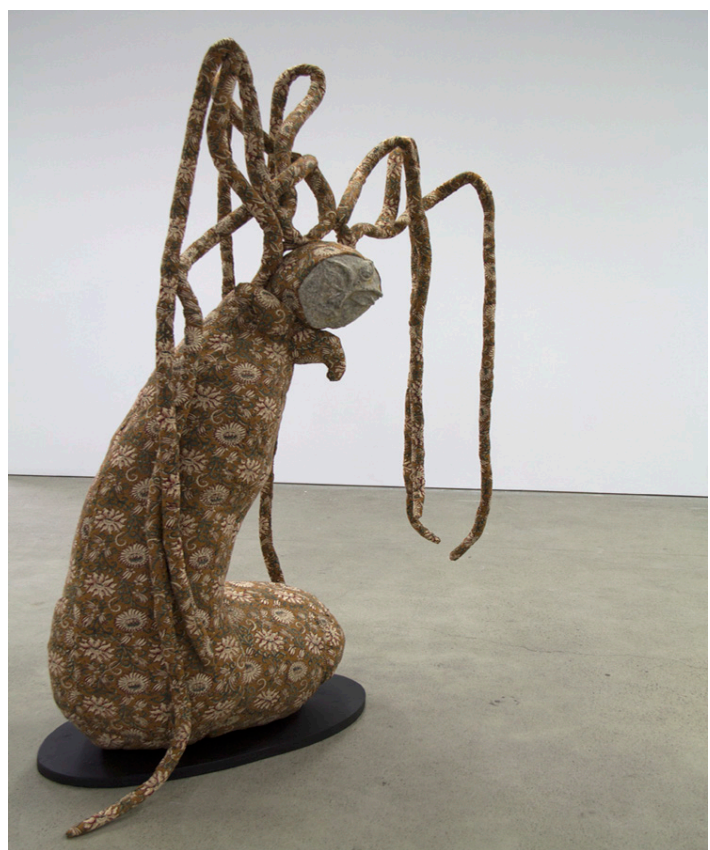

Figure I. Arati Kushwaha, Monster, 2017, steel, chicken wire, dacron, kalamkari fabric, papier-mâché. power reflects duality: on the one hand, she is fertile and warm-hearted; on the other hand, she is aggressive, a fearless destroyer who offers an alternative model of female potential and empowerment and a willingness to unleash her anger against wrongdoing, using violence as a means of liberation.

Kalamkari textiles represent both the feminist ethos and the traditional essence of Indian culture, both in the images depicted on them and in the history of their makers. Kalamkari is an ancient art form involving hand drawing and painting on cotton fabric. The term originates from Persian, in which kalam means pen and kari means craft. (The English called it chintz, ${ }^{3}$ the Dutch called it sitz, the Portuguese pintado - over time, all cloth with patterns came to be known as chintz.) In this article I explore the history of this traditional form of textile art, from sacred art to patronage by royalty through to its decline and revival in India today. 


\section{TRADITION AND PLACE}

In the annals of textile history, kalamkari represents the traditional and cultural essence of India. This is particularly evident in in the villages of Machilipatnam ${ }^{4}$ and Srikalahasti in Andhra Pradesh, which are recognised as the major centres of kalamkari painting, where the designs are block-printed or drawn by hand using vegetable dye.

Indian craftspeople have been expert in the use of vegetable dyes from ancient times. Complex mordants to hold fast the dyes or resists were traditionally used to create patterns by revealing or selectively shielding the dye from touching the cloth. Such fabrics were sought after in many countries, and the resulting patronage influenced the patterns created. In Srikalahasti, ${ }^{5}$ under Hindu rulers, kalamkari manufacture flourished under the patronage of Hindu temples, with its distinctive figure drawing and narrative depictions of mythological stories. In the early seventeenth century, when Golconda (near Hyderabad) came under Muslim rule, the designs produced in Machilipatnam catered to Persian taste.

The term kalamkari first appeared when the sutans of Golconda named the craftsmen qualamkars, those who create artwork using a pen or brush. In the nineteenth century, the art form was practised in several states including Andhra Pradesh, Madhya Pradesh, Gujarat, Orissa and Rajasthan. ${ }^{6}$

The Srikalahasti (or Kalahasti) kalamkaris had an almost exclusively religious character; scenes from Hindu epics like Ramayana and Mahabharata ${ }^{7}$ were made for temples and included Indian mythological themes. These hangings were completely hand-worked. Later under the British, they became a flourishing item of trade and were much sought after abroad.

As a celebrated form of textile workmanship, kalamkari dominated the European and French markets during the seventeenth and eighteenth centuries. From as early as the fifteenthth century, block-printed resist-dyed textiles from Gujarat and the Deccan could be found adorning Europeans and their homes. As a result, a flourishing trade in vegetable-dyed textiles existed between India and Persia for centuries. Although Persians also had knowledge of vegetable dyeing, large quantities of Indian printed material were exported to that country. The influence was reciprocal, so that the Persian trade broadened the Indian colour palette.

\section{THE ARCHAEOLOGY OF A FABRIC}

The sources available for the study of traditional cloth painting include archaeological remains from the civilisation of the Indus Valley. Spices and textiles were the principal commodities imported from India to Arabia, Africa and Persia. High-quality textiles were part of a brisk trade that included Gujarat, the Coromandel coast under the Golconda sultanate and Bengal. In the seventeenth and eighteenth centuries Bengal became a significant centre for cloth-making. Gujarat had long been a vibrant textile centre, as evidenced by samples found at Fustat or old Cairo in Egypt. The cloth fragment in Figure 2, decorated with typical motifs, was found in a tomb at Fustat. It is made of unbleached cotton cloth, with resist printing in two shades of blue. It has a circular design with a liana pattern curving inwards, a hand-fan-shaped leaf, a circular band in lighter blue and an outer decorative border band.

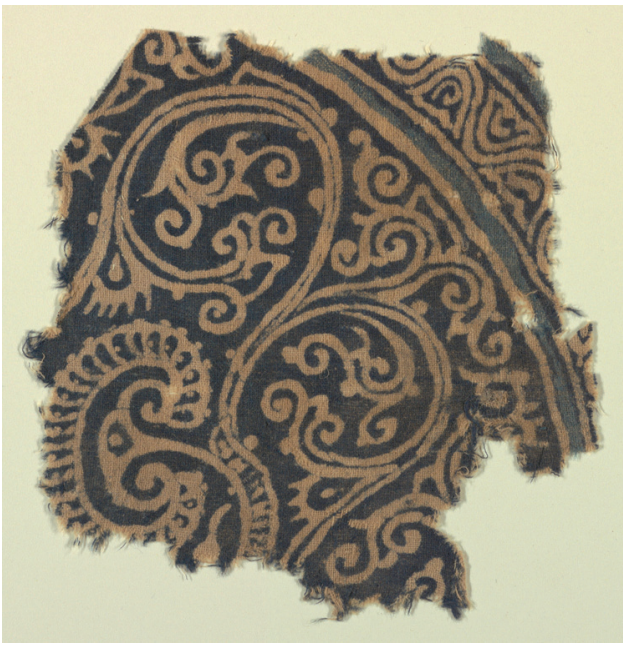

Figure 2. Indian textile fragment, 12 th- 13 th centuries, cotton, resist-printed on plain weave, $14 \times 16 \mathrm{~cm}$. Cooper Hewitt, Smithsonian Design Museum, New York. 
The small fragment of textile depicted in Figure 3 was also found at Fustat, where dry conditions helped to preserve these fragile items. Its design is Indian in origin. The Fustat fragments show either blue or red dyes. The technique used to dye was known as block and brush. The fabric is immersed in a dye which the mordant helps to fix - the mordant in the red areas was most probably painted with a brush. The patterns on these printed textiles show square blocking forming the quarter circles, with a star shape in the middle.

Under the patronage of the Mughal and Golconda sultanates, Indian textiles received considerable Islamic

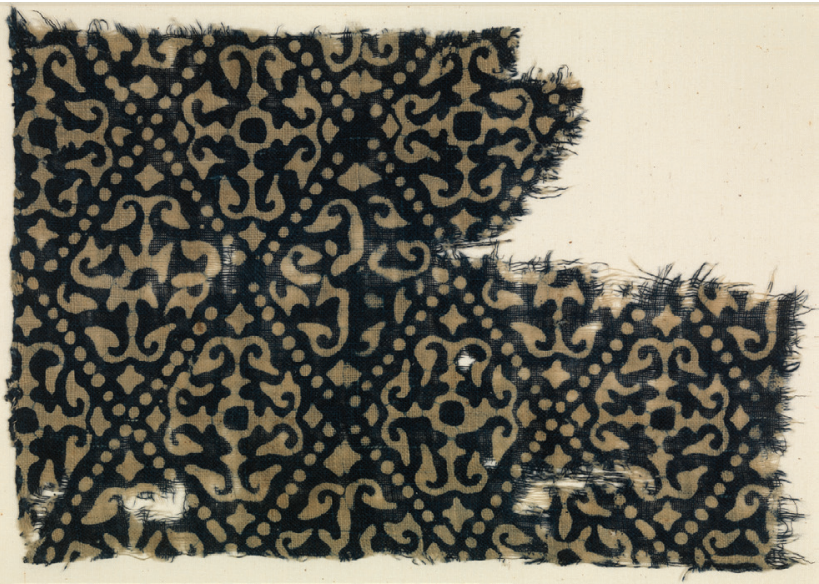

Figure 3. Textile fragment (Attributed to India. Islamic) I3th- I4th century, cotton, block-printed and resist-dyed, $16.8 \times 25.4 \mathrm{~cm}$.

The Metropolitan Museum of Art, New York. influence. In addition, during the same period, the Hindu rulers of the Coromandel region encouraged kalamkari artisans to paint hangings for their temples. By the end of the sixteenth century, Khandesh had become a prominent centre for decorative cloth production, where textile motifs included flower heads and other elements either block-printed or drawn by hand.

From the seventeenth century onwards, figurative designs became the favoured motif for artisans. As in Figure 4, the designs in the central field typically focused on musical performance, the interaction between two figures or mundane activities. Such textiles, called rumals, were used as face wipes or cushion covers.

The Dutch and English, too, came to exercise influence over kalamkari design when European demand for the cloth became common - a situation that continues today. During the late seventeenth century, handdrawn resist-dyed and mordantdyed textiles from southern India were made for the Western market, where they were known as chintz. Later, chintz was largely used in dresses; at first, some garments were made from furnishing fabrics, despite their inappropriate largescale design. From the eighteenth century, beautiful elegant designs, which were much more refined than these early prototypes, became popular for dresses. Men's clothing was also influenced by the chintz fashion craze, particularly a type of garment called a banyan.

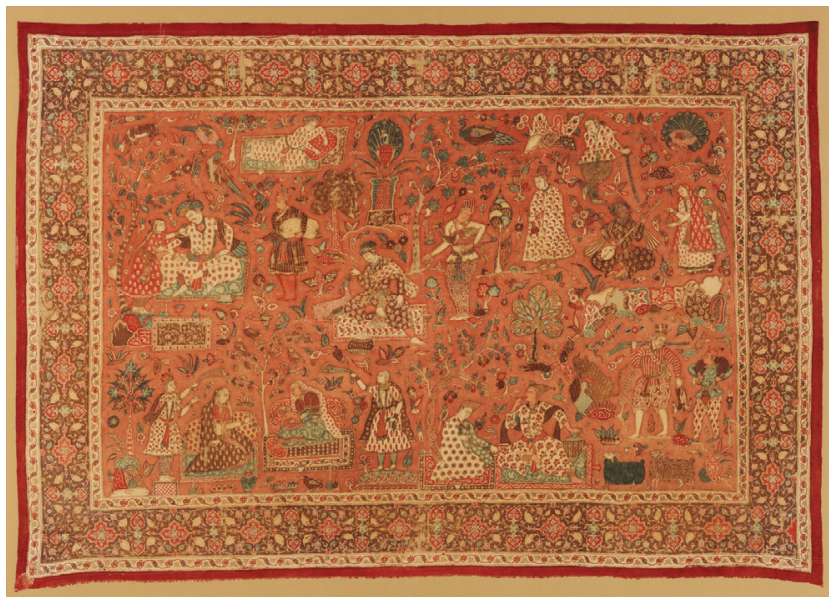

Figure 4. Kalamkari rumal (Golconda), |640-50,

cotton, plain weave, mordant painted and dyed, resist-dyed, $61 \times 91.4 \mathrm{~cm}$.

The Metropolitan Museum of Art, New York. 


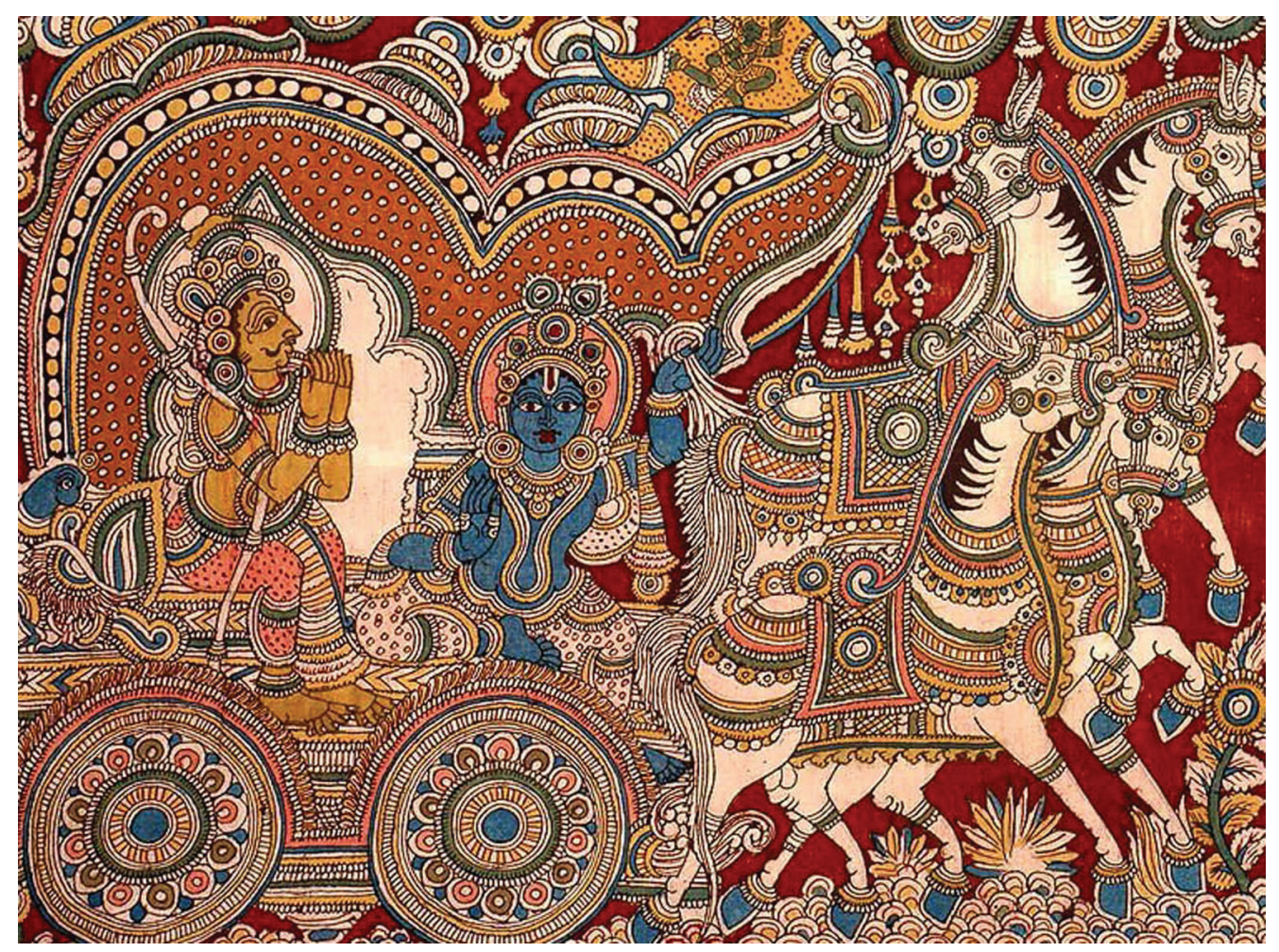

Figure 5. Kalamkari wall hanging, scene from the Mahabharata showing Lord Krishna and Arjuna,

Kalahasti, early 20th century. Salar Jung Museum, Hyderabad, India.

After 1700 the Coromandel coast became the main source of supply for the European market. During the eighteenth century, there was a decrease in demand for hand-painted and hand-printed fabrics as machine-made cloth entered the market. However, the Persians continued to patronise the craft throughout the eighteenth century. During this period the term palampore, from Hindi-Persian palang posh meaning bedcover, emerged among rich patrons in England and France who preferred kalamkari.

Under Kalahasti patronage, scenes from the great Indian epics - the Ramayana, Mahabharata and other mythological tales - were often depicted as borders on fabrics. The subjects were mainly gods such as Ganesh, Shiva and Parvathi, Durga and Brahma. Figure 5 shows part of a large kalamkari hanging depicting an episode from the Indian epic Mahabharata - Lord Krishna is shown as the charioteer of the Pandava prince Arjuna as they join in heated conversation on their impending combat with the Kurus.

In the late eighteenth century, kalamkari underwent a decline due to the flooding of the market by cheap (imitation) prints. A major revival of artisan-made fabric in fashion couture was led in 1955 by Kamala Devi Chattopadhyay. ${ }^{8}$ The Indian fashion industry came together to help the artisans of Andhra Pradesh re-establish their practice of this traditional art. More recently, veteran designer Ritu Kumar ${ }^{9}$ has also been active in reviving kalamkari textiles. Several Indian and international fashion designers are also showing beautiful kalamkari sarees in their collections and on the runway. Kalamkari sarees, dresses and blouses have once more become a huge fashion trend in India and further afield. Kalamkari is preferred by people of all generations and all over the world. There is also a thriving trade in the production of art fabrics for furnishings made from kalamkari prints. 


\section{THE TECHNIQUE OF KALAMKARI}

The printing of kalamkari fabric is a drawn-out process and can take many weeks. First, the design is drawn by hand with a very basic tool called a kalam, literally a pen. The kalam is made of bamboo, with string wrapped around part of its length. The outline is drawn in mordant using the kalam. The mordants used are naturally occurring chemicals which make the dyes fast. The next step is the drawing of the red design elements, which requires the use of alum mordant which is aluminium-based, another naturally occurring mineral - this

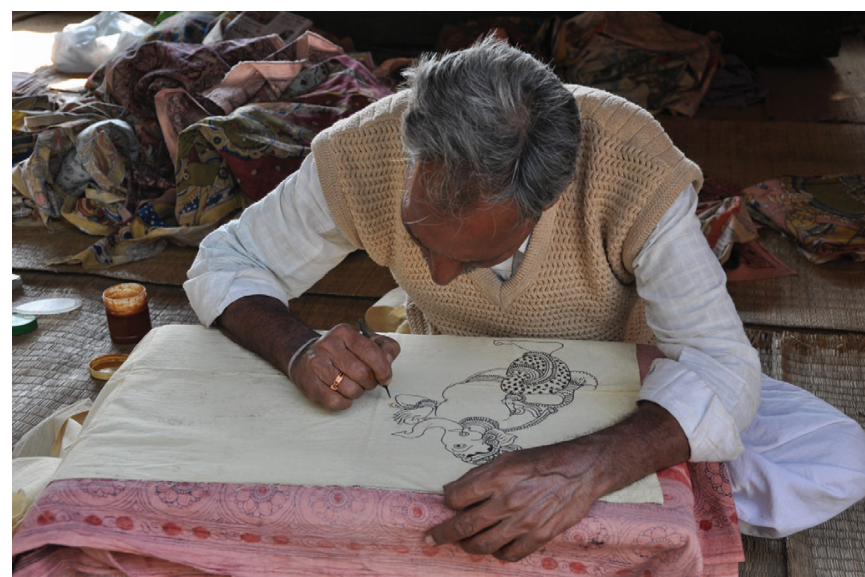

Figure 6. Hand drawing a kalamkari design. reacts with the red and fixes red dye where it is required. Then the red dye is rinsed out and wherever the alum mordant has not been applied the cloth's natural colour is retained. The same sequence follows with the application of blue. The entire textile, except for those parts to recieve colour, is shielded by covering with a wax resist for the next stage, dyeing with indigo. Only the blue areas are exposed and immersed in the dye. Then the wax is removed with boiling water. In the final stage, yellow and green are added by hand-painting, followed by several rounds of washing and supplementary dyeing.

\section{CONCLUSION}

The kalamkari technique has been admired around the globe for centuries for its mastery of intricate and aestheticately pleasing design. The product of highly skilled workmanship, kalamkari is practised in the form of block prints as well as hand-painted textiles. Still popular with women in India, it dominated the European and French markets during the seventeenth and eighteenth centuries in the form of prized furnishing textiles and wall hangings. Women have historically had a fascination for kalamkari as a fabric, leading to its popular use in clothing. The strong relationship between women and this textile type is seen in the way its designs embody the story of women's status in India through the centuries, and also the story of strong women in a challenging world. In this article I have traced the journey of kalamkari through its long history, techniques, motifs and designs. It continues to serve religious, decorative and utilitarian purposes. Nevertheless, kalamkari faces challenging times in the future from the growth of machine printing, digital printing and mass production. However, it is my hope that the hand-made will always be valued.

Born in India in 1982, Arati Kushwaha is a visual artist who completed a Master of Visual Arts at the Dunedin School of Art in 2018 with a dissertation entitled "Slow Decay: Gender Discrimination in the Indian Context." Her sculptural practice is intended to raise awareness about discrimination against women. 
I Arati Kushwaha, "Because I am a Girl, I Must Study," Scope: Art \& Design, 16 (20 I8), https://www.thescopes.org/art-anddesign-2/because-i-am-a-girl-i-must-study/.

2 Laura Amazzone, Goddess Durgā and Sacred Female Power (Lanham, Boulder, New York, Toronto, Plymouth, UK: Hamilton Books, 2010).

3 Suresh Jayaram, "What You See When You See: Art Unbound," Bangalore Mirror, I 4 November 20 I5, https://bangaloremirror. indiatimes.com/bangalore/others/what-you-see-when-you-see-art-unbound/articleshow/497721 I2.cms.

4 JBS Umanadh, "Pedanda Kalamkari Made of Natural Colours Gets Gl Tag," Deccan Herald, I0 November 20I3, https://www. deccanherald.com/content/368021/pedana-kalamkari-made-natural-colours.html.

5 Ibid.

6 Kausalya Santhanam, "Hues from Nature," Special issue with the Sunday Magazine, The Hindu, 20 June 1999, https://wmw. thehindu.com/folio/fo9906/99060320.htm

7 Ibid.

8 Kamala Devi Chattopadhyay was an Indian social reformer and freedom fighter and the driving force behind the renaissance of Indian handicrafts, hand looms, and theatre in independent India. "Remembering Kamaladevi Chattopadhyay, the unsung feminist freedom fighter," India Today, 3 April 2018, https://www.indiatoday.in/education-today/gk-current-affairs/story/whygoogle-remembers-kamaladevi-chattopadhyay-the-unsung-feminist-freedom-fighter-12035 | |-20 | 8-04-03.

9 Ritu Kumar is an Indian fashion designer specialising in one-off designs made from unique fabrics. https://www.ritukumar.com/ company-history.

Image Credits

Figure 2 Image source: https://collection.cooperhewitt.org/objects//8666577/

Figure 3 Image Source: https://www.metmuseum.org/blogs/ruminations/20 I6/indian-block-printed-textiles

Figure 4 Image Source: https://www.metmuseum.org/art/collection/search/4482 I 2

Figure 5 Image Source: https://www.utsavpedia.com/motifs-embroideries/kalamkari-art/

Figure 6 Image Source: Anilbhardwajnoida, A kalamkari artist at work. CC BY-SA 3.0, https://en.wikipedia.org/wiki/ Kalamkari\#/media/File:Kalamkari_painting.jpg 